\title{
The Study of Primary School Teachers' Performance on Number Sense
}

\author{
Yang Der-Ching and Jan Hung-Jin
}

\begin{abstract}
To examine the number sense strategies used by elementary school teachers, six elementary school teachers were interviewed by semi-structured interview method. Over one-third of the responses used rule-based methods and about $12 \%$ of participants' responses were deemed incorrect. About a half of the teachers' responses showed evidence of the use of number sense. In addition, the teacher with background in mathematics education outperformed the teachers with background in Chinese Literature Education and Sociology. Therefore, a question of utmost importance for future teacher professional development is how to help elementary school teachers develop a profound understanding of number sense.
\end{abstract}

Index Terms-Elementary-school-teachers, number-sense, rule-based-method.

\section{INTRODUCTION}

Number sense is defined as an individual understanding of numbers, operations, and their relationships, and the ability to handle numerical problems in daily-life situations. This ability is used to develop practical, flexible, and efficient strategies, such as mental computation and estimation to solve problems [1]-[3]. It has been viewed as a major topic in mathematics education in many countries around the world [3]-[10]. Studies have shown that a lack of number sense will likely result in mathematical learning difficulties [11]-[13]. This shows the importance of developing children's number sense.

Reference [14] argued that to empower students' mathematical learning, school teachers must first be empowered in their own mathematical understanding. Teachers' mathematical knowledge influences their teaching and their students' learning [15], [16]. Because student' mathematical knowledge and ability are related to what teachers teach in class [9], teachers must have a deep understanding of the content that they teach. Earlier studies have shown that students' lack of number sense may be due, in part, to their teachers' lack of number sense interfering with their ability to help their students develop number sense [17]. Previous studies have shown that elementary and middle grade students lack number sense [17]-[19]. In addition, several studies consistently showed that pre-service teachers tend to use written methods, with less than half having the ability to apply number sense methods to solve

Manuscript received June 19, 2018; revised December 23, 2018. This work was supported in part by the Ministry of Science and Technology (MOST) Taiwan under Grant MOST 105-2511-S-415-003-MY3.

D.-C. Yang is with the Graduate Institute of Mathematics and Science Education, National Chiayi University, 621 Wenlung village, Chiayi county, Chiayi, Taiwan (e-mail: dcyang@mail.ncyu.edu.tw).

H.-J. Jun is with Dalin Elementary School, Taiwan (e-mail: tles040@mail.tles.cyc.edu.tw). problems [8], [20]. Pre-service teachers' and students' lack of number sense may be due, in part, to teachers' lack of number sense [20]. While research has demonstrated that teachers play a powerful role in helping students develop number sense, there has been little research on elementary school teachers' own number sense strategies. Hence, the purpose of this study was to examine the strategies used by elementary school teachers in Taiwan when responding to number sense related questions.

\section{BACKGROUND}

\section{A. Number Sense Framework}

Number sense is a complex process involving different components; it is not easy to define. Even though different educators and researchers define number sense differently [5], there is a consensus that it should include a deep understanding of numbers, operations, and their relationships; a flexible and efficient way to handle numbers and operations; and an application of number knowledge to numerical situations [1], [9], [17], [18]. Following the lead of earlier studies and reports, this study defines number sense as including the following five components:

(N1) Understanding the basic meaning of numbers: This includes understanding the meaning of the number system, including whole numbers, fractions, decimals, percents, and their relationships, and understanding the relationships among numbers.

(N2) Recognizing the relative sizes of numbers: It means that a person is able to recognize the size of a number, particularly in comparison with one another. For example, when comparing the fractions $\frac{10}{11}$ and $\frac{14}{15}$, students could use a meaningful approach based on their recognition that $\frac{1}{11}>\frac{1}{15}$ and that $\frac{10}{11}+\frac{1}{11}=\frac{14}{15}+\frac{1}{15}$, in order to conclude $\frac{10}{11}<\frac{14}{15}$.

(N3) Being able to use multiple representations of numbers and operations: This implies that a person is able to develop and use different forms of representations, such as pictorial representations, symbolic representations, and others, to solve problems flexibly.

(N4) Recognizing the effects of an operation on numbers: This means that a person can recognize how the four basic operations affect the computational results. For example, when children are asked to find the result of $1005 \div 0.96$, they should be able to recognize that the result must be slightly greater than 1005 due to the fact that 0.96 is slightly less than 1.

(N5) Being able to judge the reasonableness of a computational result: This means that a person is able to develop flexible and efficient strategies (such as mental or estimation methods) to solve numerical problems and judge 
the how reasonable the result is.

\section{B. Teachers' Content Knowledge}

The content knowledge of teachers plays a key role in the teaching of mathematics [9], [21]. Therefore, content knowledge is an important lever to influence teaching quality. For example, as in [9], it has been emphasized that effective teaching requires teachers to have a profound understanding of mathematics. However, teachers do not always possess this kind of profound understanding. For example, as in [22], they have found that pre-service teachers possess insufficient algebra knowledge. Reference [23] found that pre-service teachers have greater difficulty in posing problems about equations pairs. In addition, as in [24], they found that Kuwaiti $8^{\text {th }}$ grade mathematics teachers tended to find exact answers to problems without judging the reasonableness of those answers. They attributed this behavior to the continual emphasis in Kuwaiti mathematics textbooks on using paper-and-pencil methods to get a correct answer. These weaknesses in teacher knowledge affect the ways they teach and influence students' problem-solving methods.

Indeed, teachers' content knowledge not only influences the effects of their teaching and the methods students use to solve problems, it is also a key to deciding whether teachers are equipped to carry out good teaching. If teachers do not have a profound understanding of mathematics, can they recognize all the conceptual connections in the mathematics they are teaching and teach accordingly? Can teachers without a solid understanding of basic content knowledge grasp the logical order of development of mathematical ideas and further, know the students' conceptual understanding of mathematics? Clearly, developing content knowledge is the foundation of developing teaching knowledge, and if we want to improve teaching quality, we must begin by enriching teachers' content knowledge [9], [14], [20].

\section{Studies of Number Sense}

Several studies have demonstrated students' lack of number sense [18]-19], [25], [26]. For example, as in [19], he found that students lack of estimation strategies and students increasingly used written computation as students progressed from grade 4 to grade 7 . Reference [27] showed that a total of 808 3rd-graders in Taiwan did not perform well on number sense assessment items. Reference [28] suggests that teachers play an important role in teaching number sense. To develop students' number sense, teachers must first understand number sense themselves. In addition, "if we want to help children develop number sense, we must first enhance teachers' number sense. Teachers empowered with knowledge and appreciation for number sense will be more likely to attend to number sense when working with students" [20].

Certainly, pre-service teachers do not appear to possess strong number sense. Reference [19] investigated 142 pre-service teachers' number sense and found that only about half could use number sense strategies (e.g., recognizing number size, judging the reasonableness of a computational result) effectively. Reference [29] noted in his study of 15 pre-service teachers' use of number sense that only one-third applied number sense methods. Two-thirds of the pre-service teachers relied heavily on written computation to solve problems, and when asked to use another method to solve problems most would respond by saying, "I don't know another way." This illustrates that a lack of number sense will limit thought and may obstruct further development of number sense for pre-service teachers, which will result in an overuse of written computation to solve problems. Reference [19] examination of 280 pre-service teachers' number sense in Taiwan found through the use of a benchmark to identify the relative size of numbers (e.g., $2 / 5<1 / 2$ and $4 / 7>1 / 2$, so $2 / 5<4 / 7$ ), that only about one-fifth used number sense to solve problems. The majority of pre-service teachers relied on rule-based methods. Indeed, the percentage using rule-based methods to solve problems was as high as to $70 \%$. It seems clear from the above literature that, due to their weak knowledge of number sense, many pre-service teachers rely on written methods to solve problems.

In sum, the results gained from pre-service teachers, as well as elementary and middle grade students' performance on number sense, show that they lack number sense [10], [18]-[20], [30]. This lack of number sense in students is likely a function of their teachers' lack of number sense. However, research regarding teachers' knowledge of number sense is still rare. If we intend to increase children's number sense, we must first investigate their teachers' number sense. Only teachers that have complete knowledge of number sense and understand the importance of number sense will be fully prepared to teach number sense in the mathematics classroom.

\section{METHOD}

\section{A. Study Design}

To examine the number sense strategies used by elementary school teachers, this study applied a semi-structured interview method to collect the participants' responses to number sense related questions. Each interview took about 1 hour. While interviewing, a number sense question was presented on an A4-sized sheet of paper on which the interviewee could use the available empty space to write down his/her problem-solving process or explanation, if necessary. In addition, the researcher asked interviewees to explain their thoughts by thinking aloud. The whole process, including verbal responses and behavior, was video recorded.

\section{B. Participants}

Six elementary school teachers in southern Taiwan were selected to participate in the study. They were given the following pseudonyms. Their backgrounds information was obtained during the interviews.

Betty is a female teacher who has taught mathematics for 8 years. Her undergraduate degree is in Chinese Literature Education; therefore, teaching mathematics in elementary schools is a big challenge for her. Vicky is a female teacher who has taught mathematics for 12 years. Her undergraduate degree is in Education. Tracy is a female teacher who has taught mathematics for 15 years. Her undergraduate degree is in Sociology. She is interested in teaching mathematics. Helen is a female teacher who has taught mathematics for 5 years. Her undergraduate degree is in Education. For Tracy, teaching math makes her feel powerless. Tom is a male teacher who has taught mathematics for 14 years. His undergraduate degree is in Mathematics Education. He likes 
to teach mathematics. Jane is a female teacher who has taught 3 years. Her undergraduate degree is in Mathematics Education.

\section{Instrument}

Based on the number sense components detailed above, a total of 20 interview questions were constructed, with each of the five components addressed by four questions. The questions were reviewed by the researchers involved in this study as well as three elementary school mathematics teachers who have master's degrees and whose studies had focused on number sense. All agreed that these questions could be used to examine the elementary school teachers' number sense. To further confirm that the questions were appropriate, a pilot study was run with several math teachers. This pilot study showed that the 20 questions required an excessive amount of time for the interview process, causing many interviewees to lose patience; therefore, one question from each component was deleted and some questions were revised. The deleted questions were chosen because they were easy for teachers to calculate answers for (e.g., Chen drove a van to Taipei from Pintung. He added gasoline and spent 2489 NT dollars. One liter of gasoline cost 31.2 NT dollars. How many liters did he add? (1) 8 liters (2) 80 liters (3) 800 liters (4) 8000 liters). As a result, the formal instrument used in this study consisted of 15 questions with three questions representing each of the five number sense components (see Appendix).

\section{Data Analysis}

This study analyzed and summarized participants' strategies based on their responses and reflective notes [18], [20]. The researchers determined the strategies used by participants based on the following criteria:

1) Number sense-based method (NS-based method): The participant's strategies exhibited one or more of the five components in the definition of number sense.

2) Partial NS-based method: Although the participant used some concept of number sense to solve a problem, he or she also used some rules or formulas to solve the problem.

3) Rule-based method: The participant could only use written or formula-based methods to solve the problem, even when encouraged to use non-algorithmic approaches.

4) Wrong explanation: The participant did not seem to understand the concept clearly, explained the strategies vaguely, or guessed the answer.

Two researchers reviewed the transcripts independently to categorize each answer as correct or incorrect, and then we coded again for making sure the type of strategy they used. These initial reviews produced over $93 \%$ agreement in the categorization of participant responses. The remaining responses were reexamined and discussed by the coders to resolve which of the above criteria best described the participant's responses.

\section{RESULtS}

\section{A. Strategies Used by Elementary School Teachers}

Table I reports the frequencies and percentages of the strategies used by elementary school teachers. Data showed that the elementary school teachers performed the best on the number sense component "understanding the basic meaning of numbers." Results showed that 13 out of the 18 responses applied NS-based methods. One response used a partial NS-based method, one response used a rule-based method, and three responses were incorrect. In addition, sample teachers performed second best on the number sense component "recognizing the effects of an operation on numbers." 12 out of the 18 responses were determined using NS-based methods, one response used a partial NS-based method, three responses applied rule-based methods, and two responses were incorrect. This shows that the teachers performed relatively well on questions about both of these number sense components as compared with the other components. Sample teachers performed the worst on the number sense component "Being able to judge the reasonableness of a computational result." Only four out of 18 responses used NS-based methods, 10 out of 18 responses used rule-based methods, and four response was incorrect. Sample teachers also did not perform well on the number sense component "Recognizing the relative sizes of numbers." Only six out of 18 responses used NS-based methods, one response used a partial NS-based method, nine responses used a rule-based method, and two responses were incorrect.

TABLE I: FREQUENCY AND PERCENTAGES OF STRATEGIES USED BY ELEMENTARY SCHOOL TEACHERS

\begin{tabular}{|c|c|c|c|c|c|c|}
\hline & \multicolumn{5}{|c|}{ Components } & \multirow{2}{*}{ Total } \\
\hline & N1 & $\mathrm{N} 2$ & N3 & $\mathrm{N} 4$ & N5 & \\
\hline \multicolumn{7}{|l|}{ Correct } \\
\hline NS-based method & 13 & 6 & 8 & 12 & 4 & $43(47.8 \%)$ \\
\hline Partial NS-based & 1 & 1 & 0 & 1 & 0 & $3(3.3 \%)$ \\
\hline Rule-based method & 1 & 9 & 10 & 3 & 10 & $33(36.7 \%)$ \\
\hline Wrong explanation & 0 & 0 & 0 & 0 & 0 & $0(0 \%)$ \\
\hline \multicolumn{7}{|l|}{ Incorrect } \\
\hline Partial NS-based & 1 & 0 & 0 & 0 & 0 & $1(1.1 \%)$ \\
\hline Rule-based method & 0 & 0 & 0 & 0 & 0 & $0(0 \%)$ \\
\hline Wrong explanation & 2 & 2 & 0 & 2 & 4 & $10(11.1 \%)$ \\
\hline
\end{tabular}

Note. N1: Understanding the basic meaning of numbers; N2: Recognizing the relative sizes of numbers; N3: Being able to use multiple representations of numbers and operations; N4: Recognizing the effects of an operation on numbers; N5: Being able to judge the reasonableness of a computational result

Furthermore, data also showed that about $47.8 \%$ of elementary school teachers could apply number sense-based method to solve problems and about $36.7 \%$ of sample teachers used Rule-based method.

Table I reports the six elementary school teachers' responses and their use of strategies when responding to number sense related questions. The data show that $40 \%$ of A's responses utilized an NS-based method, $27 \%$ of the responses used a rule-based method, one response included a correct answer but wrong explanation, and $26 \%$ of the responses were incorrect, including $13 \%$ using a rule-based method and $13 \%$ with wrong explanations. B used NS-based methods for only $27 \%$ of her responses, less frequently than any of the other teachers. In addition, $13 \%$ and $33 \%$ of B's responses utilized partial NS-based methods and rule-based methods, respectively, and $27 \%$ of B's responses were incorrect. C used NS-based methods for $47 \%$ of her responses. In addition, $7 \%, 20 \%$, and $7 \%$ of C's responses were categorized as correct with partial NS-based methods, 
rule-based methods, and wrong explanations, respectively. Moreover, $20 \%$ of C's responses were incorrect. All of D's responses were correct, with $40 \%$ and $60 \%$ utilizing NS-based methods and rule-based methods, respectively. $80 \%$ of E's responses utilized NS-based methods, $13 \%$ used rule-based methods and 7\% were incorrect. Finally, $73 \%$ of F's responses used NS-based methods and $27 \%$ used rule-based methods.

\section{B. Differences in Number Sense Performance on the Five Components}

Table II summarizes the frequencies of strategies used by the elementary teachers when responding to number sense related questions from each of the number sense components. Recall that there were three questions for each component, and thus 15 teacher responses for each component. The data show that the teachers had the weakest performance on being able to judge the reasonableness of a computational result. Only two of the 15 responses to questions from this category applied NS-based methods to solve the problems. Both were made by Tom, who majored in mathematics education. In contrast, nine of the 15 responses used a rule-based method and four out of 15 were incorrect.

TABLE II: NUMBER SENSE STRATEGIES USED By ELEMENTARY SCHOOL

\begin{tabular}{lcccccc}
\hline \multicolumn{7}{c}{ TEACHERS } \\
\hline Correct & Betty & Vicky & Tracy & Helen & Tom & Jane \\
NS-based & $6(40 \%)$ & $4(27 \%)$ & $7(47 \%)$ & $6(40 \%)$ & $12(80 \%)$ & $11(73 \%)$ \\
Partial NS & $0(0 \%)$ & $2(13 \%)$ & $0(0 \%)$ & $0(0 \%)$ & $0(0 \%)$ & $0(0 \%)$ \\
Rule-based & $4(27 \%)$ & $5(33 \%)$ & $4(27 \%)$ & $9(60 \%)$ & $2(13 \%)$ & $4(27 \%)$ \\
Wrong & $1(7 \%)$ & $0(0 \%)$ & $1(7 \%)$ & $0(0 \%)$ & $0(0 \%)$ & $0(0 \%)$ \\
exp. & & & & & & \\
\hline Incorrect & & & & & \\
Partial NS & $0(0 \%)$ & $1(7 \%)$ & $0(0 \%)$ & $0(0 \%)$ & $0(0 \%)$ & $0(0 \%)$ \\
Rule-based & $2(13 \%)$ & $1(7 \%)$ & $0(0 \%)$ & $0(0 \%)$ & $1(7 \%)$ & $0(0 \%)$ \\
Wrong exp & $2(13 \%)$ & $2(13 \%)$ & $3(20 \%)$ & $0(0 \%)$ & $0(0 \%)$ & $0(0 \%)$ \\
\hline
\end{tabular}

To understand this situation, it is helpful to examine the individual questions for this component (questions 9, 10, and 15). No sample teachers utilized NS-based method to solve question 9 (John uses a calculator to calculate the following math problem: 0.488 times 182.45 equals 890356 ; however, when he is writing down his answer he forgot to add a decimal point. Which answer choice corresponds to the correct decimal placement? (1) 0.890356 (2) 89.0356 (3) 8.90356 (4) 890.356). Four teachers misjudged the missing decimal point position by using a memorized rule (the multiplicand has a three-digit decimal and the multiplier has a two-digit decimal; thus the product of multiplication should have $3+2=5$ decimal places). For example:

Betty : I will directly count how many decimal places there are; there are 5 decimal places. That is why the answer is 8.90356 .

Vicky : This concept should have been learned before. I just count how many decimal places there are and there are 5 decimal places in total ( 2 decimal places and 3 decimal places). Then, we should put the decimal point at the fifth decimal place from the end, which is 8.90356 .

Tom : 3 decimal places and 2 decimal places are 5 decimal places, so I have put the decimal point after 8 , which is 8.90356 .

Betty, Vicky, Helen, and Tom all solved the problem by counting decimal places, which caused failure in solving the problem.

Tracy also solved the problem using the same method; however, she got the correct answer because she knew there should be a zero at the end of the answer $(5 \times 8=40)$. Therefore, her method should be classified as rule-based. For example,

Tracy : Because 0.488 has 3 decimal places and 182.45 has 2 decimal places so in principle we will put the decimal point at the position back from the last number by 5 decimal places. However, because $(5 \times 8=40)$., it should have a zero at the end so it means there is a zero after 890356 . In fact, it does not, so there should only be 4 decimal places, and that's why I chose 89.0356.

Five teachers solved the problem by counting the decimal places rather than using a benchmark $(0.488$ is about 0.5$)$ to estimate an approximate value (a value of about 180 multiplied by 0.5 is about 90 ). They all mentioned that this is the way teachers and textbooks have told them how to solve this kind of problem. One common response was: "the mathematics books used to tell us to solve this type of problem by this method." When further inquiries were made, they would ask, "Do you know a different approach to solving this problem?" This shows that they cannot utilize benchmarks in situations like question 9 to reach correct answers. It seems that written algorithms may have limited their thinking and reasoning abilities. By judging the decimal point position in the answer by counting digits without noticing the number size shows that teachers lack of number sense. In sum, all five teachers were unable to use benchmarks in question 9 to judge the reasonableness of a computational result.

For question 10 (see Appendix), four teachers could not accurately judge the relation among numbers. One teacher obtained the correct answer by using rule-based methods. For example:

\section{Tracy : I will add a zero to 400 because $5 \times 4=20$. \\ Tracy : If the number at the end was sprayed by ink then that would be 2, 4, 6, 8, 0, and then it should be an even number. Fan's explanation includes two other people's explanations, in which the number at the end is 2.4.6.8.0. I don't care about Fan's answer. Although his answer is an odd number, the number is an even number; so, Fan is right.}

From the first part of Tracy's response, we can see that she noticed that the answer 400 had to be wrong by using a rule-based method. Tracy decided on an answer by knowing that an even number multiplied by 5 will result in a number in which 0 appears at the end.

Tom, who majored in mathematics education, was the only one to correctly judge the answer meaningfully. Tom could logically reason about the answer:

Tom: I think the answer is (3). Because the range of "(3) It is an even number for sure" is larger. 400 and $4 \square 0$ are also even numbers. Even number includes 400 and $4 \square 0$, therefore (3) must be the answer.

In this problem, three teachers responded incorrectly. They had misconceptions about numbers and operations. For 
example:

Helen : Here $(1325 \times 4 X X=588300)$ there are two 0 s and one 5 , but this doesn't mean that two 0 s can produce two 0s. I think if the middle number is an even number then we can make it right, because 5 multiplied by an even number will produce 0 . The product will have two 0 s, so the end of the number will have to be a 0 , and the middle number could be a $2,4,6$, or 8 , which means there could be two $0 \mathrm{~s}$ at the end of the number.

Helen used a rule-based method to incorrectly explain that there are two $0 \mathrm{~s}$, but she only notices one possibility. It is a mathematical myth that she only considered the end of the numbers, and thought they let a product have two 0s when multiplying each other. If teachers can think about the relation between numbers and operations to further understand their meaning, they then will be able to realize that the end number of the multiplicand will be $25 \times 4=100$ and $25 \times 8=200$.

Both Betty and Vicky guessed when responded to question 10; for example, Betty said: "I calculated mentally and found out that 400 will have an extra 0 because $5 \times 4=20,400$ more, which I think is too large. 410 is also too large. 40 would be appropriate." Furthermore, Vicky said: "the question requires that the answer should be $4 \square 0$ and an even number as well. For example, I assumed the answer is 440, and while doing the calculation noticed that it is incorrect. Again, I think the third choice is definitely an even number but the range is too big, so I guessed that it could be 2."

For question 15 , only the response made by Tom applied a NS-based method to solve the problem. Tom applied an estimation strategy based on combining the two printers' capabilities: " 8 minutes can print about 300 pages and 35 minutes is less than 8 times 5 minutes. Moreover, 300 times 5 is about 1500 pages which is less than 1655 pages. Therefore, two printers cannot print 1655 pages within 35 minutes."

Four teachers obtained the correct answer by using rule-based methods. These teachers could not use number sense to judge the reasonableness of the answer and tended to utilize a similar rule-based method to obtain an answer. For example,

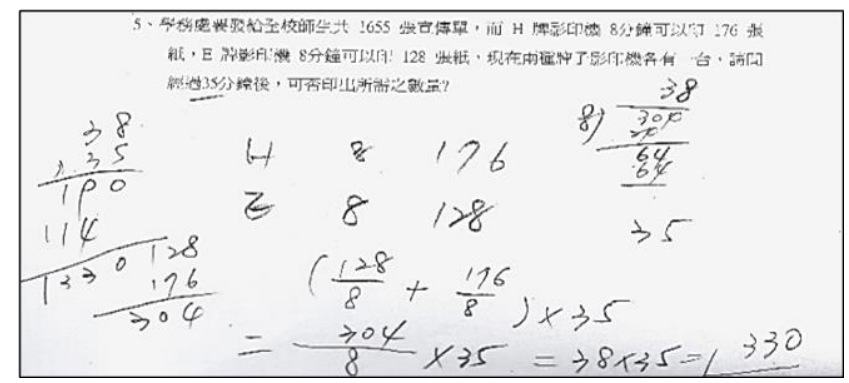

Fig. 1. The written record of Helen's problem-solving method for question 15 .

Helen-11501: I will count the page numbers of one minute for each printer, add them, and then multiplied by 35 (See Fig. 1). Therefore, the answer is $(128 / 8+176 / 8) \times 35=$
$304 / 8 \times 35=38 \times 35=1330.1330$ is less than 1655 . Hence, two printers could not print 1655 pages within 35 minutes.

R-11502 : Do you have different approach?

Helen-11502 : This is the only one I know.

Tracy, Vicky, and Betty all used a similar rule-based method to solve this problem.

As a group, the teachers also demonstrated weakness on the number sense component "recognizing the relative sizes of numbers". Table 2 shows that, of the 15 responses to questions based on this component, five teachers used NS-based methods, one teacher used a partial NS-based method, seven teachers used rule-based methods, and two teachers answered incorrectly. Generally, teachers preferred using a rule-based method to answer these questions, especially question 3 (Xiao-mei has been given fifteen thousand dollars as her allowance. She will spend 4,200 dollars on clothing, spend $\frac{15}{52}$ of the allowance on food, and spend 0.38 of the allowance on recreational activities. What does she spend the most on? 1) Clothing 2) Food 3) Recreation 4) cannot be determined from the information provided).

This question was used to examine whether sample teachers could apply $\frac{1}{3}$ as a benchmark to solve this question efficiently (e.g., $\frac{4200}{15000}=\frac{42}{150}$ is less than $\frac{1}{3}\left(=\frac{50}{150}\right), \frac{15}{52}$ is also less than $\frac{1}{3}\left(=\frac{15}{45}\right)$ and 0.38 is greater than $\frac{1}{3}$, so the answer is 0.38 for recreation). However, data showed that four out of five teachers used a rule-based method and one teacher gave a wrong explanation for question 3 .

Betty : Well... I felt that it was hard to decide, so I calculated directly. $15000 \times 0.38=5700$, $15000 \times \frac{15}{52}$ is about $4500(150 \div 52=2.9 \ldots$ $3 \times 150=4500)$, so the answer is 3 .

Vicky : I changed it to a decimal like this: $\frac{15}{52}=15 \div 52$, $\frac{4200}{15000}=\frac{7}{25}=7 \div 25$. Based on the computation, I knew which expense was larger.

Tracy : I wanted to figure out the ratio of 4200 dollars, which is $\frac{4200}{15000}$ and after reducing $\frac{4200}{15000}$ to $\frac{7}{25}, \mathrm{I}$ converted the decimal 0.38 to the fraction $\frac{38}{100}$. After reducing the fraction $\frac{38}{100}$ to $\frac{19}{50}$, I changed $\frac{7}{25}$ to $\frac{14}{50}$. Comparing $\frac{19}{50}$ and $\frac{14}{50}$, I saw that $\frac{19}{50}>\frac{14}{50}$. Also $\frac{19}{50}$ and $\frac{15}{52}$ can be compared because when we divide one thing equally, the more we divide, the smaller each part will be. In addition, $19>$ 15 , so $\frac{19}{50}$ is bigger.

Tom : I changed them to fractions like this: $0.38=\frac{38}{100}$; the percentage for clothing is $\frac{4200}{15000}$, which is also $\frac{7}{25}=\frac{14}{50} \cdot \frac{38}{100}$ was reduced to $\frac{19}{50}$ and then I knew that the fraction $\frac{19}{50}$ is the biggest. Obviously $\frac{19}{50}>\frac{14}{50}$ as for $\frac{19}{50}$ and $\frac{15}{52}$, because $\frac{19}{50}$ $>\frac{15}{50}$, ah, $\frac{15}{50}>\frac{15}{52}$, I choose number 3 as the answer. 
Betty, Vicky, Tracy and Tom all used traditional written methods. They converted all the values to fractions or decimals and then compared them to each other rather than use number sense to solve the problem. This means that when encountering complicated problems, these teachers showed a tendency to use the written method to reach a solution.

At first, Helen thought that $\frac{15}{52}$ was about $\frac{15}{45}$, but when comparing fractional sizes, she exhibited the incorrect belief that the bigger denominator represents the bigger fraction:

Helen-10303: $\frac{15}{52}$ can be simplified to $\frac{15}{45}$ which is $\frac{1}{3}$, and the denominator 52 is bigger than the denominator 45 so that means it is also bigger $\operatorname{than} \frac{1}{3} \cdot \frac{1}{3}$ is about 0.333 so $\frac{15}{52}$ is bigger than 0.333 . Then, according to the denominators, 52 is bigger than 38; I think that spending $\frac{15}{52}$ on food is bigger than spending 0.38 on recreation.

R-10304 : Do you have different methods to solve this problem?

Helen-10304: I don't know.

Overall, these responses showed that the teachers preferred to use a rule-based method to solve problems. When questions included complex fractions and decimals, the teachers tended to convert the fractions to decimals or decimals to fractions in order to make comparisons.

\section{DISCUSSION}

This study examined the number sense performance and strategies used by five elementary school teachers in Taiwan when responding to number sense related questions. The results show that the responses of Tom, who majored in mathematics education, presented several characteristics which are different from the other elementary teachers who did not have mathematics education backgrounds (e.g., Chinese Literature, Education, and Sociology). Tom had superior number sense performance to the other four elementary teachers. About $80 \%$ of his responses applied NS-based methods, in contrast to $27 \%$ to $47 \%$ of the other four teachers' responses. This seems to reflect the mathematics education training in Tom's undergraduate background.

Tom was both more flexible and efficient than the other four elementary teachers in developing and using benchmarks such as $\frac{1}{2}, \frac{1}{3}$, and $\frac{1}{4}$ to solve problems. Of the 15 questions in the interview, seven called for applying benchmarks. Tom was able to apply the benchmarks to solve 6 of those 7 questions. In addition, Tom was more successful in judging the reasonableness of a computational result than the other four elementary teachers. For example, the other teachers were unable to judge the reasonableness of a computational result for any of the three questions related to this number sense component. However, Tom's responses to two of the questions reflected an ability to judge the reasonableness of a computational result.

Finally, Tom was more flexible in his logical reasoning than the other sample teachers. For example, in responding to question 10 Tom reasoned that the answer "It is an even number for sure" included both 400 and $4 \square 0$, where $\square$ is an even number. Thus, he concluded that this answer was more general than either of the other options. It seems reasonable to believe that Tom, who had a specific mathematics background, would exhibit better performance on number sense than elementary teachers who did not have mathematics backgrounds. This result reflects those of earlier studies that suggest that teacher's content knowledge plays a key role in teaching mathematics and students' learning [9], [16], [21].

The results of this study also confirm that, on the whole, teachers' use of number sense-based methods is relatively poor. About two fifths and one third of the teachers' responses used number sense-based methods and rule-based methods, respectively. Moreover, about one ninth of the responses were incorrect. This finding is consistent with previous studies that showed that preservice teachers performed poorly on the use of number sense-based methods [8], [20]. Several earlier studies have shown that fourth, fifth, sixth, and eighth graders in Taiwan perform poorly on number sense [27], and this finding has been established in studies conducted in other countries as well [10], [18], [19], [26], [30]. The teachers in this study, like the pre-service teachers, elementary school students and middle grade students studied elsewhere, demonstrated poor performance on number sense. This indicates that if we want to promote students' number sense performance, it will be important to reinforce school teachers' number sense first. This supports the statement of the Principles and Standards for School Mathematics that "effective teaching requires knowing and understanding mathematics" [9]. It is easier for students to learn number sense if teachers can develop it firstly. When teaching, teachers who know number sense well can make students attend to it naturally [20].

Looking more specifically, these results show that the teachers in this study performed the worst on the number sense component "being able to judge the reasonableness of a computational result." In fact, only 2 out of 15 responses were found to reflect the use of a number sense-based strategy when responding to questions related to this component. Rule-based strategies were much more common, such as counting decimal places in order to determine the placement of the decimal point in a multiplication problem. This result is in accord with previous studies that have shown that fifth, sixth, and eighth graders have similar troubles when dealing with such problems [26], and that elementary and middle grade students, and pre-service teachers performed the worst on 'being able to judge the reasonableness of a computational result' [8], [20].

Moreover, this research showed poor performance by sample teachers on a range of mathematics problems related to determining the reasonableness of answers. This parallels the situation with Kuwaiti eighth graders and teachers who value exact answers and do not consider the reasonableness of the exact answers they obtain [24]. A previous study has argued that students in Taiwan perform the worst on the number sense component "judging the reasonableness of computational results" most likely because Taiwanese mathematics textbooks offer few examples and exercises related to this component and because of an over-reliance on "drill and practice" in mathematics teaching [27]. That the teachers in the present study performed the worst on "judging 
the reasonableness of computational results" may well be due to their own learning experiences being highly focused on written computation.

Indeed, about one third of the teachers' responses in this study used written methods to find answers to the questions. The teachers neglected the context of the problems at hand or the relationship of the numbers in the problems and could not get away from the rules of mathematical operations. This impeded their use of number sense. Previous studies have shown how mathematics teaching in Taiwan focuses on training students' written computation skills [27]. These written methods assuredly influence the way students think and do not enhance their number sense. Does the lack of number sense in students result from insufficient number sense in teachers? As in [20], they claimed that the reason students lack number sense ability is probably due to teachers shortfalls, leaving them unprepared to teach students regarding number sense. Based on the results of this study, it may be that sample teachers do not currently have the necessary profound understanding of number sense to help their students to develop number sense.

\section{CONCLUSION}

The results of this study raise concerns about whether teachers are equipped to take on that role. Only two fifths of the teachers' responses reflected the use of number sense-based methods and only one out of the five teachers could judge the reasonableness of a computational result. Moreover, the teacher with a background in mathematics education outperformed the teachers with backgrounds in education, Chinese Literature Education, and Sociology. This suggests that the background of a teacher will affect their performance on number sense.

In fact, teachers' understanding of mathematical knowledge influences their teaching and their students' learning [9], [15], [16]. Reference [14] stated, to "empower students to think mathematically, teachers must first be so empowered" (p. 105). Reference [9] also highlights the need for teachers to "know and understand deeply the mathematics they are teaching and be able to draw on that knowledge with flexibility in their teaching tasks" (p. 17). It is reasonable to believe that a priority in future teacher professional development should be helping elementary school teachers develop a profound understanding of number sense while learning how to teach number sense. It is our hope that this study will raise awareness regarding the needed development of school teachers' number sense, which should be incorporated in future teacher professional training programs.

\section{IMPLICATIONS AND FUTURE RESEARCH}

Due to the limitation of a small sample size, these findings must be interpreted with caution. However, we highlight two implications. First, results from this study add to the emerging body of literature on the broad lack of number sense in various populations [20]. Earlier studies have shown that elementary and middle grade students lack number sense [19], [27] and that pre-service teachers tend to use written methods with less than half able to apply number sense to solve number sense related problems [8], [20].

Second, the findings presented here indicate the need to improve elementary school teachers' number sense. Teachers do not possess a profound understanding of number sense and without this they are unable to aid students to develop number sense. This supports the statement of the Principles and Standards for School Mathematics [9] in that "effective teaching requires knowing and understanding mathematics." (p. 17). Furthermore, previous studies have reported the importance of mathematics teachers' subject matter knowledge and assert that the mathematical knowledge teachers possess has a profound impact on what and how they teach [6], [9], [14], [16], [21].

Future studies are needed to examine questions such as: a) Do teachers from different locales in both Taiwan and abroad face similar obstacles with respect to number sense? b) How can teachers' number sense and teaching of number sense skills be promoted through professional development? c) What kind of number sense materials can be used to help teachers develop number sense efficiently?

\section{REFERENCES}

[1] A. McIntosh, B. J. Reys, and R. E. Reys, "A proposed framework for examining basic number sense," For the Learning of Mathematics, vol. 12, no. 3, pp. 2-8. November 1992.

[2] J. Sowder, "Estimation and Number Sense," Handbook of Research on Mathematics Teaching and Learning, NY: Macmillan, 1992, pp. 371389.

[3] D. C, Yang and M. N, Li, "Assessment of animated self-directed learning activities modules for children's number sense development," Journal of Educational Technology and Society, vol. 16, no. 3, pp. 44-58, January 2013.

[4] J. Anghileri, Teaching Number Sense, UK: Continuum International Publishing Group Ltd, 2006.

[5] D. B, Berch. "Making sense of number sense: Implications for children with mathematical disabilities" Journal of Learning Disabilities, vol. 38, no. 4, pp. 333-339, Jul-Aug, 2005.

[6] J. Bobis, "Number sense and the professional development of teachers," Beyond written computation, Perth, Western Australia: Mathematics, Science \& Technology Education Centre, Edith Cowan University, 2004, pp. 160-170.

[7] E. Dunphy, "The primary mathematics curriculum: Enhancing its potential for developing young children's number sense in the early years at school," Irish Educational Studies, vol. 26, no. 1, pp. 5-25, February 2007.

[8] R. Menon, "Pre-service teachers' number sense," Focus on Learning Problems in Mathematics, vol. 26, no. 2, pp. 49-61. Spring, 2004.

[9] National Council of Teachers of Mathematics (NCTM), Principles and Standards for School Mathematics, Reston, VA: NCTM, 2000.

[10] L. Verschaffel, B. Greer, and E. Corte, "Whole number concepts and operations," Second handbook of research on mathematics teaching and learning, Charlotte, NC: Information Age Publishing, 2007, pp. 557-628.

[11] M. M. Mazzocco and R. E. Thompson, "Kindergarten predictors of math learning disability," Learning Disabilities \& Practice, vol. 20, no. 3, pp. 142-155, August 2005.

[12] N. C. Jordan, J. Glutting, and C. Ramineni, "The importance of number sense to mathematics achievement in first and third grades," Learning and Individual Differences, vol. 20, no.2, pp. 82-88, April 2010.

[13] R. Gersten, N. C, Jordan, and J. R, Flojo, "Early identification and interventions for students with mathematics difficulties," Journal of Learning Disabilities, vol. 38, no. 4, pp. 293-304, Jul-Aug, 2005.

[14] L. Ma, Knowing and Teaching Elementary Mathematics: Teachers' Understanding of Fundamental Mathematics in China and the United States, Mahwah, NJ: Lawrence Erlbaum, 1999.

[15] D. L, Ball, H. C, Hill, and H. Bass, "Knowing mathematics for teaching: Who knows mathematics well enough to teach third grade, and how can we decide?" American Educator, vol. 29, no.1, pp. 14-46, fall, 2005.

[16] $\mathrm{D} . \mathrm{Ng}$, “Indonesian primary teachers' mathematical knowledge for teaching geometry: Implications for educational policy and teacher preparation programs," Asia-Pacific Journal of Teacher Education, vol. 39, no. 2, pp. 151-164, April 2011. 
[17] Y. C. Lin, D. C. Yang, and M. N. Li, "Diagnosing students' misconceptions in number sense via a web-based two-tier test," Eurasia Journal of Mathematics, Science \& Technology Education, vol. 12, no. 1, pp. 41-55. January 2016.

[18] Z. Markovits and J. T. Sowder, "Developing number sense: An intervention study in grade 7," Journal for Research in Mathematics Education, vol. 25, no. 1, pp. 4-29, January 1994.

[19] R. Menon, "Elementary school children's number sense," International Journal for Mathematics Teaching and Learning, vol. 57 no. 1, pp. 1-16. 2004

[20] D.C. Yang, R. E. Reys, and B. J. Reys, "Number sense strategies used by pre-service teachers in Taiwan," International Journal of Science and Mathematics Education, vol. 7, no. 2, pp. 383-403, April 2009.

[21] D. L. Ball, M. H. Thames, and G. Phelps, "Content knowledge for teaching: What makes it special?" Journal of Teacher Education, vol. 59, no. 5, pp. 389-407. November 2008

[22] W. Van Dooren, L. Verschaffel, and P. Onghena, "The impact of preservice teachers' content knowledge on their evaluation of students' strategies for solving arithmetic and algebra word problems," Journal for Research in Mathematics Education, vol. 33, no. 5, pp. 319-351. November 2002.

[23] C. Isik and T. Kar, "The analysis of the problems posed by the pre-service teachers about equations," Australian Journal of Teacher Education, vol. 37, no. 9, pp. 93-113, September 2012.

[24] A. Alajmi and R. Reys, "Reasonable and reasonableness of answers: Kuwaiti middle school teachers' perspectives," Educational Studies in Mathematics, vol. 65, no. 1, pp. 77-94. May 2007.

[25] A. McIntosh, B. J. Reys, R. E. Reys, J. Bana, and B. Farrell, Number Sense in School Mathematics: Student Performance in Four Countries, Perth, Edith Cowan University, 1997.
[26] D. C. Yang, "Number sense strategies used by 6th-grade students in Taiwan," Educational Studies, vol. 31, no. 3, pp. 317-334. Jan. 2007.

[27] D. C. Yang and M. N. Li, "An investigation of $3^{\text {rd }}$ grade Taiwanese students' performance in number sense," Educational Studies, vol. 34 no. 5, pp. 443-455. March 2009.

[28] D. C. Yang, "Developing number sense through real-life situations in school of Taiwan," Teaching Children Mathematics, vol. 13, no. 2, pp 104-110. September 2006.

[29] D. C. Yang, "Investigating the strategies used by pre-service teachers in Taiwan when responding to number sense questions," School Science and Mathematics, vol. 107, no. 7, pp. 293-301. Nov. 2007.

[30] M. Heuvel-Panhuizen, Children and Mathematics, Utrecht, The Netherlands: Freuenthal Institute, University of Utrecht, 2001.

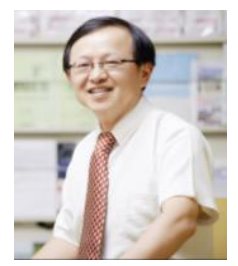

Der-Ching Yang is a distinguished professor of mathematics education at National Chiayi University. His current research interests include number sense, mathematics textbooks studies, and mathematics teaching and learning.

Hung-Jin Jan is a mathematics teacher at Dalin Elementary School in Taiwan. His current research interests include number sense and mathematics teaching and learning. 